\title{
AUTONOMOUS CONTROL SYSTEM FOR A SQUEEZE MODE MR VIBRATION ISOLATOR IN AN AUTOMOTIVE ENGINE MOUNT
}

\author{
Maciej ROSÓk ${ }^{*}$ Bogdan SAPIŃSKI ${ }^{*}$ \\ *Faculty of Electrical Engineering Automatics Computer Science and Biomedical Engineering, Department of Automatics and Biomedical Engineering, \\ AGH - University of Science and Technology, Al. Mickiewicza 30, Kraków, Poland \\ ${ }^{* *}$ Faculty of Mechanical Engineering and Robotics, Department of Process Control, \\ AGH - University of Science and Technology, Al. Mickiewicza 30, Kraków, Poland
}

$\underline{\text { mr@agh.edu.pl, deep@agh.edu.pl }}$

\begin{abstract}
The investigated autonomous control system for a squeeze mode magnetorheological (MR) vibration isolator is based on an ultra-low power microcontroller MSP430F5529. The design structure of the control system and the dedicated real-time system are briefly presented and the laboratory testing data are summarised.
\end{abstract}

Key words: MR Vibration Isolator, Control System, Controller

\section{INTRODUCTION}

The last decade has witnessed a major interest in squezeemode MR vibration isoslators (VI-MRs) (Farjoud et al., 2011; Kim et al., 2008; Zhang et al., 2011). The majority of previous research has been focused mainly on theoretical studies, e.g. Jolly and Carlson (1996) and Stanway et al. (2000). It is worthwhile mentioning that certain solutions for these type of VI-MRs have been patented (Kim, 2012; Sapiński, 2013).

The investigated autonomous control system (ACS) is designed to be used for control of a prototype squeeze-mode MR vibration isolator (VI-MR). The VI-MR is intended for use as an actuating element in a semi-active engine automotive mount system designed to reduce the engine's vibrations due to fluctuating inertia forces (caused by unbalanced element of the crank system), to fluctuations of the drive torque transmitted from the engine onto the drive system components and to the action of some random forces (Kamiński and Pokorski, 1983; Snamina and Sapiński, 2014).

The ACS is based on an ultra low power microcontroller MSP430F5529 (MSP430) (Texas Instruments INC, 2013). Prior to the fabrication of ACS, testing was done on a previously developed power driver dedicated for VI-MR and based on an integrated interface VNH2SP30-E (Rosół and Sapiński, 2014).

The ACS requires a dedicated real-time clock system, to enable the measurement of process variables and to develop the control method with the predetermined sampling period (Philip and Laplante). The quaranteed constatnt sampling period enables the usie of the theory of discrete control systems in developing control algorithms for VI-MR. Besides such approach allows to employ model-based design method in simulation, testing and implementation of regulators on the target hardware platform.

Measurement data from the ACS are monitored and processed using a serial bus Controller Area Network (CAN) (Bosch $\mathrm{GmBH}, 1991)$. This bus was selected as it is intended for use in control of the VI-MR to be installed in the engine mount in the vehicle where CAN acts as the primary data transmission interface.

The engineered ACS was tested in the laboratory conditions in two configurations: the open loop and in the feedback loop (with a PID controller) systems. Testing was done under the loading applied through the electromagnet coil whose resistance and induction were similar to the parameters of the control coil in the VI-MR.

\section{DESIGN STRUCTURE}

The block diagram of the ACS, shown in Fig. 1, comprises the following units: the MSP430 block with analogue and digital signal outputs, the measurement block, the CAN interface, the powersupply and the USB interface.

The key component of the ACS is the MSP430 supporting the measurement and control application. The MSP430 features high program memory and data memory capacity, numerous integrated peripherals (USB, SPI, 12C, UART, an A/D converter, a multiply unit) and the supply voltages can be generated via an USB port. The major technical parameters of the MSP430 are summarised in Tab. 1.

The MSP430, the measurement block and the CAN bus block are supplied with voltages $+5 \mathrm{~V}$ and $+3 / 3 \mathrm{~V}$ from the power supply block. The ACS may be supplied via a micro-USB port $(+5 \mathrm{~V})$ or from a power supply unit delivering the voltage in the range $(+3.3,+12) \mathrm{V}$.

The measurement block incorporating the system for conditioning four analogue signals enables the gain and offset control, so the sensors operating in the voltage range $\pm 10 \mathrm{~V}$ can be easily connected to the ACS. The voltage range handled by the measurement block necessitates the use of a DC/DC $+5 \mathrm{~V} / \pm 15 \mathrm{~V}$ converter in the power supply block. The MSP430 has an integrated USB interface which can be utilised for programming and data exchange with the microprocessor. The current levels to be han- 


\section{DE GRUYTER}

OPEN

Maciej Rosół, Bogdan Sapiński

Autonomous Control System for a Squeeze Mode MR Vibration Isolator in an Automotive Engine Mount

dled by the USB interface block are limited to $100 \mathrm{~mA}$ and the data lines $\mathrm{D}+$ and $\mathrm{D}$ - are surge-voltage protected.

The CAN bus block enables the ACS communication with peripheral devices via the CAN bus. This block is implemented on an integrated SPI/CAN converter and a CAN transceiver. The maximal data transmission throughput is $1 \mathrm{Mbit} / \mathrm{s}$.

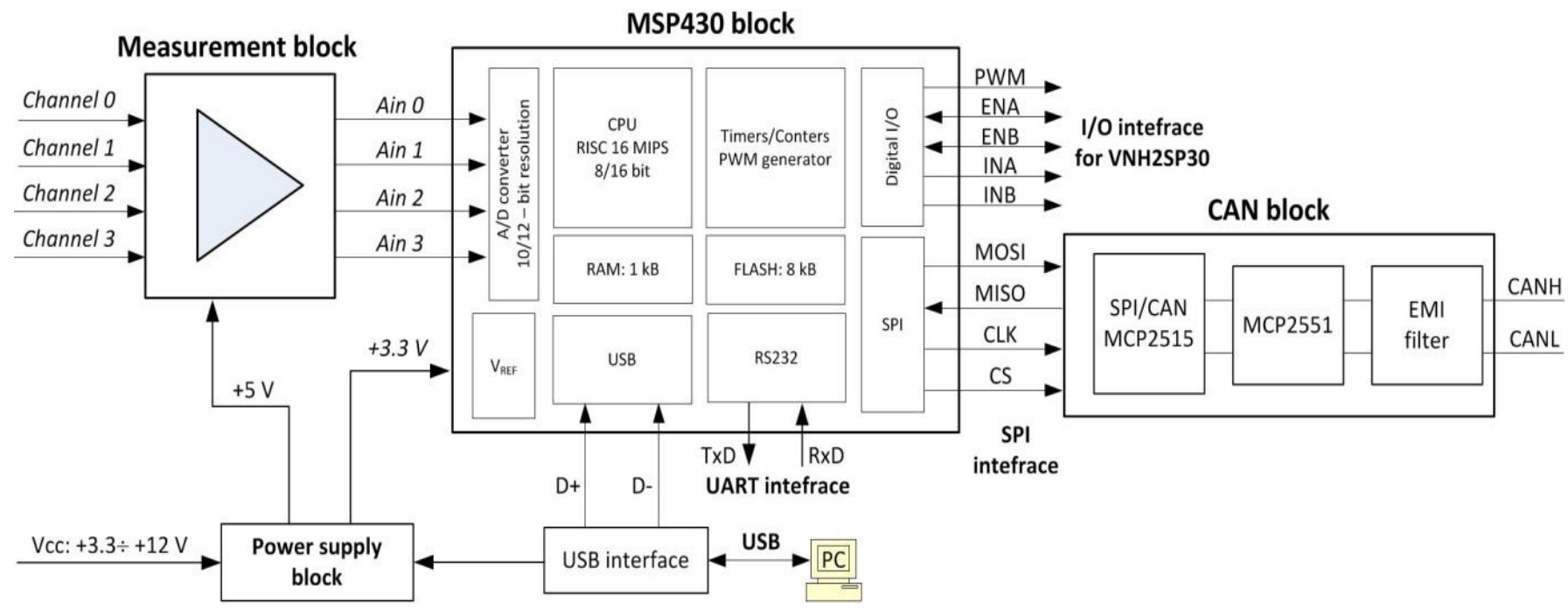

Fig. 1. Block diagram of the ACS

Tab. 1. Technical parameters of MSP430

\begin{tabular}{|l|r|}
\hline \multicolumn{1}{|c|}{ Parameter } & \multicolumn{1}{|c|}{ Description } \\
\hline Program memory & $128 \mathrm{kB}$ \\
\hline Data memory SRAM & 8+2 kB (additional 2 kB without \\
USB)
\end{tabular}

\section{TESTING}

\subsection{Laboratory setup}

The schematic diagram of the laboratory set-up for ACS testing is shown in Fig. 2. The power interface and ACS are supplied from the battery $+12 \mathrm{~V}$. The monitoring and data acquisition are supported by a purpose-developed application written in the Lab-View and activated on a PC. The data transmission between the ACS and PC is effected via a sbRIO-9639 card equipped with the CAN interface (ACS connection) and the Ethernet (PC connection). The power interface ensures the current levels 11-12 A to be as required in the electromagnet coil.

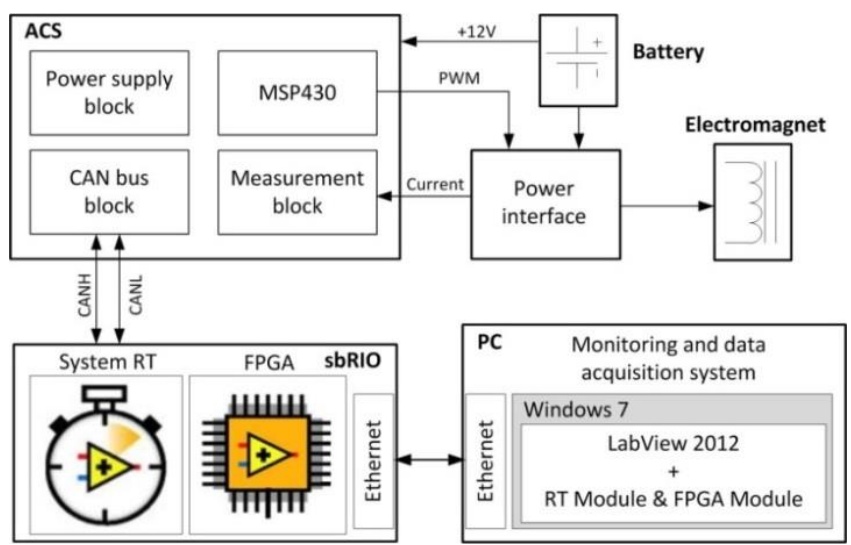

Fig. 2. Block diagram of the test configuration

The application supporting the operation of measurement sensors and control of the electromagnet coil is MSP430 enabled. The primary function of this application, written in the $\mathrm{C} / \mathrm{C}++$ language in the Code Composer Studio (CCS) environment is to generate the command signal basing on the current measured in the electromagnet coil, so that the current should be maintained on the preset level. Besides, the application configures and handles the digital analogue signals from the microcontroller (including the signals from the PWM signal generator, an $A / C$ converter and the SPI interface supporting the communication with the SPI/CAN converter). To lend the controller a deterministic feature, the control algorithm is activated in the procedure of interruption from the timer. The time interval of this interruption is set to be $1 \mathrm{kHz}$. This value was selected basing on the transmissibility characteristics of the power interface, obtained for the VI-MR, shown in Fig. 3. The gain Mg is derived from formula (1).

$\left|M_{g}\right|=20 \log _{10}\left(\frac{I(f)}{\alpha(f)}\right)$ 
where: I(f) - amplitude of current in the electromagnet coil at the frequency $\mathrm{f}, \alpha(\mathrm{f})$ - amplitude of the PWM factor at the frequency f.

It appears that the maximal frequency of variations of the command signal is $188 \mathrm{~Hz}$, which means that the minimal sampling frequency of the control algorithm should be equal to 376 $\mathrm{Hz}$. The set-up for ACS testing is shown in Fig. 4.

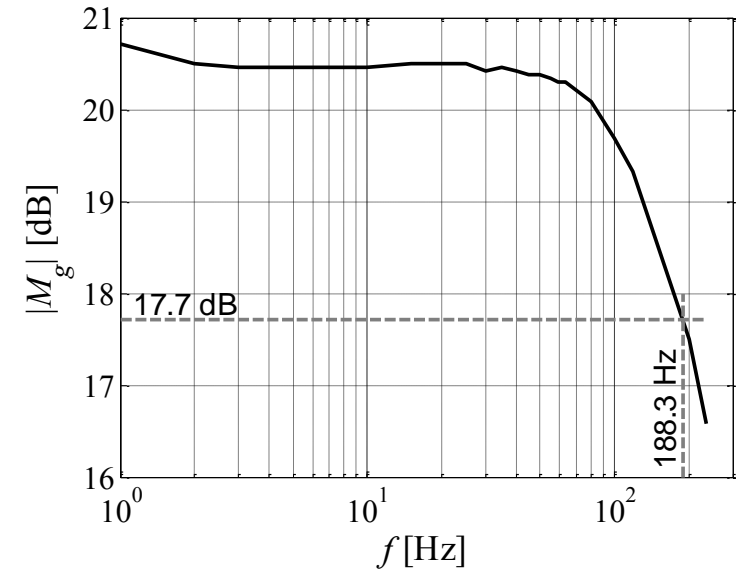

Fig. 3. Transmissibility characteristics of the power interface for the VI-MR

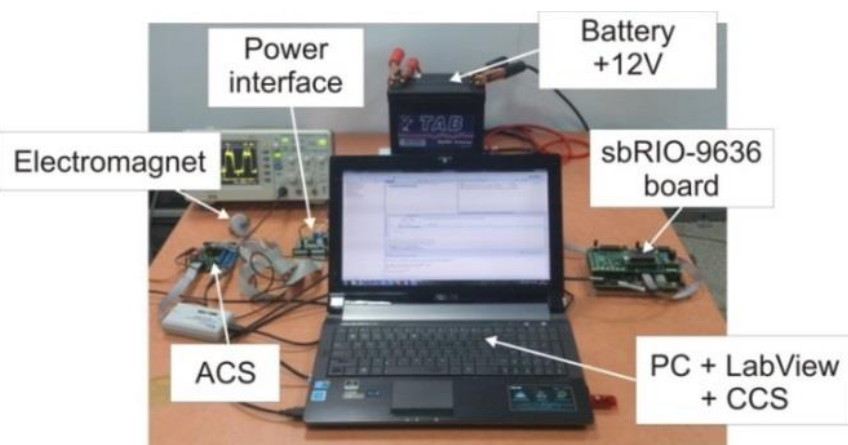

Fig. 4. Set-up for ACS testing

\subsection{Results}

Testing was done on the ACS system in the open loop configuration (ACS-O) and in the closed-loop configuration (ACS-PID). The applied control signal was current i in the electromagnet coil. Electrical parameters of the electromagnet coil were: resistance $1.059 \Omega$, induction $1.13 \mathrm{mH}$.

The PI version of the PID controller, used in the ACS-PID system, is governed by the equation (2).

$$
\begin{aligned}
& u(t)=u_{0}+K_{p} \varepsilon(t)+\frac{1}{T_{i}} \int_{o}^{t} \varepsilon(\tau) d \tau \\
& \varepsilon(t)=i_{0}-i(t)
\end{aligned}
$$

where: $\mathrm{u}(\mathrm{t})$ - control, $\mathrm{u}_{0}$ - control value in the steady state, $\varepsilon(\mathrm{t})$ - control error, $\mathrm{i}_{0}$ - preset current level in the coil, $\mathrm{K}_{\mathrm{p}}$ - controller gain, $\mathrm{T}_{\mathrm{i}}$ - integration time.

The parameters of the $\mathrm{PI}$ controller chosen using the parametric optimisation methods are: $\mathrm{K}_{\mathrm{p}}=49.3 ; \mathrm{T}_{\mathrm{i}}=1.74 \times 10^{-4}$. The integration function of the $\mathrm{PI}$ controller is approximated by the rectangle method.
Tab. 2. Time required for reaching the preset current level in the control coil

\begin{tabular}{|c|c|c|c|}
\hline ACS & $1 \mathrm{~A}$ & $3 \mathrm{~A}$ & $5 \mathrm{~A}$ \\
\hline ACS-O & $1.92 \mathrm{~ms}$ & $2.1 \mathrm{~ms}$ & $1.96 \mathrm{~ms}$ \\
\hline ACS-PID & $1.32 \mathrm{~ms}$ & $1.36 \mathrm{~ms}$ & $1.16 \mathrm{~ms}$ \\
\hline
\end{tabular}
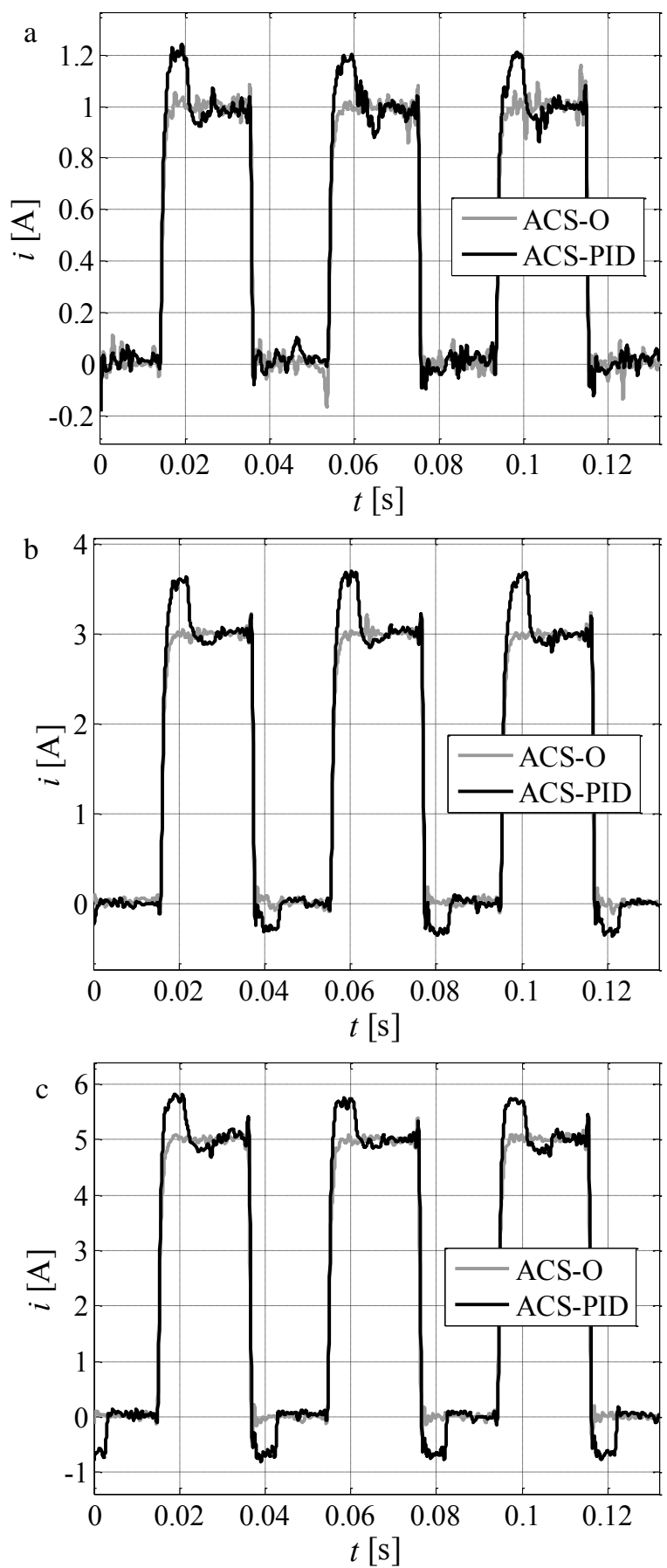

Fig. 5. Time patterns of current $i$ : a) $\left.\left.\mathrm{i}_{0}=1 \mathrm{~A}, \mathrm{~b}\right) \mathrm{i}_{0}=3 \mathrm{~A}, \mathrm{c}\right) \mathrm{i}_{0}=5 \mathrm{~A}$

Testing of the ACS-O and ACS-PID system was done for the pre-defined PWM signal frequency $(5 \mathrm{kHz})$ and the duty cycle $\alpha$ was varied from 0 to 1 with the step 0.1 . As it was mentioned previously, the primary function of the ACS-PID system is to stabilise the current level in the electromagnet coil. This configuration of the system was tested for the preset current levels $i_{0}: 1,2,3,4$, 6 A. The patterns of the PWM control and current in the coil 
registered for the ACS-O and ACS-PID configurations are shown in Fig. 5 , for $i_{0}=1 A, i_{0}=3 A$ and $i_{0}=5 A$. The current $i(t)$ plots show that the required current level $i_{0}$ was reached in the electromagnet coil, both in the ACS-O and the ACS-PID configuration. Application of the $\mathrm{PI}$ controller allowed a $30 \%$ reduction of the time needed to reach the preset current level (see Tab. 2). One has to bear in mind, however, that for smaller values of $i_{0}$ these time intervals can become decidedly shorter.

\section{SUMMARY}

This paper summarises the structure design of an MSP430based ACS and laboratory test data are provided. The engineered ACS was tested in the laboratory conditions in two configurations: the open loop and in the feedback loop configuration (with a PID controller). Testing was done under the loading applied to the power interface VI-MR through an electromagnet coil. Experimental results show that application of the PI controller allowed a $30 \%$ reduction of the time needed to reach the preset current level and force produced by VI-MR in real application.

It is worthwhile to mention that the selected microcontroller MSP430 has a sufficient computational power to implement algorithms and allows for expanding the ACS structure such that it should incorporate extra sensors and actuators. ACS tests will be repeated once the final version of the vibration isolator VI-MR has been developed.

\section{REFERENCES}

1. Bosch GmBH (1991), CAN Specification, Version 2.0, Stuttgart, www.bosch-semiconductors.de.

2. Farjoud A., Craft M., Burke W., Ahmadian M. (2011), Experimental investigation of MR squeeze mounts, Journal of Intelligent Material Systems and Structures, 22, 1645-1652.

3. Jolly M. R., Carlson J. D. (1996), Controllable Squeeze-film Damping using MR fluid, Proc. of Actuator, Bremen, Germany, 333-336.

4. Kamiński E., Pokorski J. (1983), Dynamics of automobile suspensions and drive systems, WKŁ, Warsow.

5. Kim J. H. (2012), Damping control device with magnetorheological fluid and engine mount having the same, United States Patent Application Publication US 2012/0132492A1.

6. Kim K. J., Lee Ch. W., Koo J. H. (2008), Design and modeling of semi-active squeeze film dampers using magnetorheological fluids, Smart Materials and Structures, 17, 035006, 12.

7. Phillip. A. Laplante (1997), Real-Time Systems Design and Analysis: An Engineer's Handbook, $2^{\text {nd }}$ ed., 59.95, IEEE Press,. Piscataway, N.J., USA.

8. Rosół M, Sapiński B. (2014), Prototyping of a control system for a magnetorheological vibration isolator, Modelling in Engineering (to be published).

9. Sapiński B. (2013), Vibration isolator with MR fluid, Bulletin of Polish Patent Office, 17 (1034), 27.

10. Snamina J., Sapiński B. (2014), Analysis of an automotive vehicle engine mount based on squeeze-mode MR damper, Journal of Cracow University of Technology (to be published).

11. Stanway R., Sims N. D., Johnson A. R. (2000), Modelling and control of a magnetorheological vibroisolator, Proc. of SPIE, 3989, 184-193.

12. Texas Instruments Inc. (2013), MSP430F5529 mixed signal microcontroller. Technical data, www.ti.com.

13. Zhang X. J., Farjud A., Ahmadian M., Guo K. H., Craft M. (2011), Dynamic Testing and Modelling of an MR Squeeze Mount, Journal of Intelligent Material Systems and Structures, 22, 1717-1728.

The work has been accomplished under the research project No. PBS 1/A6/3/2012. 